Pak. j. sci. ind. res. Ser. A: phys. sci. 2016 59(2) 90-95

\title{
Liberation Studies of Padhrar Coal By Using Fractionation Method, XRD Analysis and Megascopic and Microscopic Techniques
}

\author{
Muhammad Shahzad*, Zulfiqar Ali, Yasir Majeed, Zaka Emad, \\ Muhammad Aaqib and Bilal Adeel \\ Mining Engineering Department, University of Engineering \& Technology, Lahore, Pakistan
}

(received October 2, 2014; revised September 14, 2015; accepted December 31, 2015)

\begin{abstract}
This research study aims to establish liberation characteristics of Padhrar coal by using various methods including fractionation method, megascopic and microscopic analysis and X-ray diffraction (XRD) technique. Sieve analysis revealed that more than $83 \%$ of the coal lied in the medium particle size range of $-26.670+6.680 \mathrm{~mm}$. The results of fractionation analysis indicated that most of the sulphur was found in the smaller sized fractions having particle size less than $6.680 \mathrm{~mm}$ while most of the ash was found to be associated at larger particle size $(+26.670 \mathrm{~mm})$ and at relatively smaller particle size $(-6.680 \mathrm{~mm})$. It was found that Padhrar coal consisted of three major minerals namely; quartz, pyrite and kaolinite. These minerals were found to be associated with organic matter at different particle size levels, thus making the nature of the Padhrar coal more complex for its cleaning.
\end{abstract}

Keywords: liberation study, Padhrar coal, fractionation method, XRD of coal, megascopic analysis, microscopy of coal

\section{Introduction}

Coal is a complex heterogeneous mixture of organic and inorganic constituents (Ural, 2007). These are usually present in the form of solid, liquid, and gaseous phases intimately mixed with each other (Liu et al., 2005; Vassilev and Vassileva, 1996). Although, the nature of coal (rank and type) and the utilization of coal in different processes are primarily dependent upon its organic components (Liu et al., 2005; Vassilev and Tascon, 2003), but the amount and type of inorganic matter also play a key role in defining the end use.

The inorganic matter of coal is generally classified into three major classes namely; dissolved salts, discrete particles, and inorganic elements mingled within organic constituents (Vessilev and Vassileva, 1996; Ward, 2002). Dissolved salts are usually present in the pore water of coal. Discrete inorganic particles which may be crystalline or non-crystalline represents true mineral components of coal (Ward, 2002). The crystalline mineral matter typically comprised of oxides-hydroxides, sulphides-sulphosalts, sulphates, silicates, carbonates, phosphates, vanadates, tungstates, chlorides, native elements, and other mineral classes (Ural, 2007; Vassilev and Vassileva, 1996).

Punjab area of Pakistan has a coal resource potential of 596 million tonnes. Coal reserves in Punjab are

*Author for correspondance; E-mail: m.shahzad87@uet.edu.pk located in the Eastern and the Central Salt Range and in the Makerwal area of Surghar range. In the recent past, the coal resources of Punjab have been defined to be located in the seven zones, Padhrar coal zone is one of them containing coal resource of 63.83 million tonnes (Snowden, 2010).

Until now, Padhrar coal could not find its applications in electricity production and cement industry due to its low quality. It contains large amounts of mineral matter and sulphur. Few attempts were made to upgrade the quality of Padhrar coal through physical cleaning methods (Shahzad et al., 2015). But these were not proved successful due to the lack of or poor knowledge of liberation characteristics of Padhrar coal.

Most of the difficulties associated with coal utilization arise from inorganic mineral matter rather than maceral composition. Mineral matter act as a diluent in coal, displacing combustible material with non-combustible matter (Ward, 2002).

The form and quantity of inorganic components have profound effect on the behaviour of coal during combustion. Quartz particles give rise to erosion in the grinding mills and on exposed surfaces of the furnace. Sulphur in various forms have long been recognized as a cause of corrosion of furnace and boiler pipes as well as the major source of environmental pollution during burning of coal. Slagging in furnace is mostly associated with iron sulphides, siderite or calcite (Creelman and 
Ward, 1996). These problems demand the removal of undesirable elements from coal before its final use in the industry. Since the nature and distribution of mineral matter present in the coal, have fundamental effect on the coal cleaning technologies, the characterization and liberation studies of the mineral matter are critically important (López and Ward, 2008; Ward, 2002).

Several methods are available to determine the type and amount of mineral matter and to assess their associations with coal macerals. Fractionation method was used by several researchers (Cloke et al., 2002; Spears and Booth, 2002) to study associations of mineral components with organic material of coal in different size fractions. Microscopic (petrographic) study of coal has long been used to study the kinds and amounts of macerals and minerals. It was also utilized to determine the degree of coalification by measuring the percentage of reflectance in reflected light (Valentim et al., 2006). The powder X-ray diffraction (XRD) is probably the most widely employed technique both for qualitative and quantitative analysis of minerals in coal (Ritz and Klika, 2010; Saikia et al., 2007; Ward et al., 2001; Wertz and Collins, 1998).

This study aims to determine the quality of coal from Padhrar area of district Khushab, Punjab, Pakistan. Another objective of the present research is to establish the liberation characteristics of this coal. Moreover, this paper also describes the nature of associations of mineral matter with coal matrix.

\section{Materials and Methods}

Coal sample in bulk amount was collected from Punjab Mineral Development Corporation (PUNJMIN) coal mine located in Padhrar coalfield of Punjab, Pakistan. Since primitive methods of mining are being used in Punjab coal mines, it was not possible to take sample by using mechanical means.

The sample was collected from a coal stock pile in accordance to ASTM D-2234 and ASTM D-6883. The production of the mine was about 80-90 metric tonnes per day. There were three piles each containing approximately 20 metric tonnes of coal (the amount of coal that was loaded into a single truck). These stockpiles contained fresh coal that was mined at that day. The height of each coal pile was measured to be less than 1.5 meter. The top surface of each pile was levelled. For the collection of gross sample, four points were selected in each coal pile in such a way that the pile was divided into four equal parts by drawing two perpendicular lines on its top surface and the centre of each quarter was selected as one of the four sampling points. Four increments each having an amount of $5 \mathrm{~kg}$ were taken from each point by using a shovel. The number of increments collected in this way were totaled to be 48 and the total amount of the gross sample collected from three coal stockpiles was found approximately equal to $240 \mathrm{~kg}$. The gross sample was preserved into two plastic drums already lined with plastic sheets of $0.4 \mathrm{~mm}$ size along their inner walls.

The gross sample was crushed by using Denver laboratory jaw crusher set at $3 / 4$ inches. The gross sample was further divided into four sub samples by the standard procedure of coning and quartering. Sieve analysis was performed on one sub-sample. The individual sieve fractions were weighed and subsequent weights were recorded. After that, all the size fractions were further ground to $-0.177 \mathrm{~mm}$ by using laboratory disc mill. These ground fractions were analyzed for their ash and sulphur contents following ASTM standard test methods (ASTM D-3174, ASTM E-775). All these tests were conducted on air-dried basis.

ASTM standards (D-3173, 3174 and 3175) were used to perform a proximate analysis on another coal sub sample obtained from bulk sample which was first ground to $-0.177 \mathrm{~mm}$. The percentage of total sulphur was also determined for this sub-sample by using standard test method (ASTM E-775). Bomb calorimeter was utilized to find out the calorific value of coal sample.

Megascopic pictures of randomly selected coal pieces were captured on the site while microscopic photographs were taken by using MM6C-AF-2 microscope (Fig. 1) in the reflected light. A very fine size coal sample $(-0.150 \mathrm{~mm})$ was prepared and subjected to X-ray diffraction analysis using computer controlled Philips XPERT PRO diffractometer system with $\mathrm{Cu} \mathrm{K \alpha}$ radiation having a wavelength of $1.54 \AA$. The scan range was kept starting from $4.990^{\circ}$ and ending at $120.000^{\circ}$ with step size of $0.035^{\circ}$. The total measuring time was observed to be $8.15 \mathrm{~min}$. The data thus obtained was stored in a digital format. JCPDS Powder Diffraction File was used to identify the minerals from diffractogram.

\section{Results and Discussion}

Sieve analysis. The results of sieve analysis are given in Table 1. The graph between cumulative mass percentage and average aperture size of each fraction 


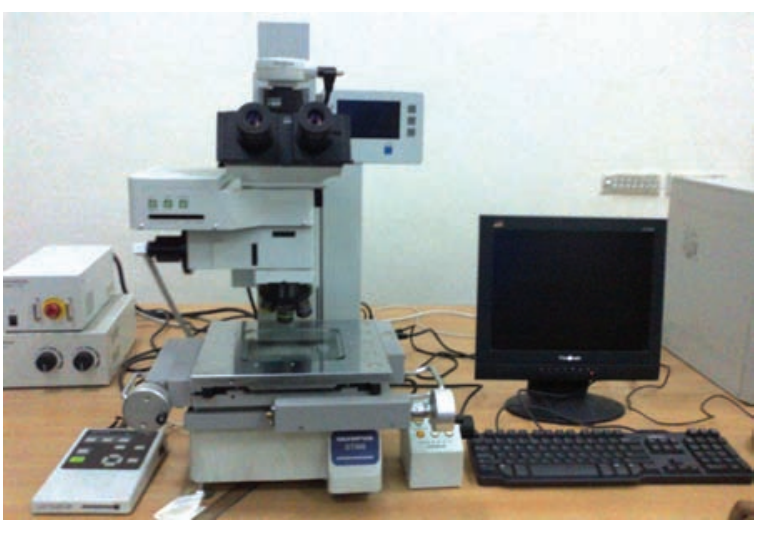

Fig. 1. MM6C-AF-2 microscope.

is shown in Fig. 2. It may be noted that about $83.48 \%$ of the total mass lies in the size range of -26.67 $\mathrm{mm}+6.68 \mathrm{~mm}$.

Proximate analysis. The results of proximate analysis and combustion analysis (sulphur and calorific value) of the Padhrar coal samples are given in Table 2. The results obtained from the proximate analysis categorize

Table 1. Masses of the fractions retained at sieves of different mesh size

\begin{tabular}{lccc}
\hline \hline \multirow{2}{*}{$\begin{array}{l}\text { Fraction size } \\
(\mathrm{mm})\end{array}$} & \multirow{2}{*}{$\begin{array}{c}\text { Mass retained } \\
(\%)\end{array}$} & \multicolumn{2}{c}{ Cumulative mass } \\
\cline { 3 - 4 }+38.00 & 0.00 & 100.00 & 0.00 \\
$-38.00+26.67$ & 1.57 & 98.43 & 1.57 \\
$-26.67+18.86$ & 22.50 & 75.93 & 24.07 \\
$-18.86+13.33$ & 28.34 & 47.59 & 52.41 \\
$-13.33+6.68$ & 32.64 & 14.95 & 85.05 \\
$-6.68+3.327$ & 8.47 & 6.48 & 93.52 \\
$-3.327+1.680$ & 2.90 & 3.58 & 96.42 \\
-1.680 & 3.58 & 0.00 & 100.00 \\
\hline \hline
\end{tabular}

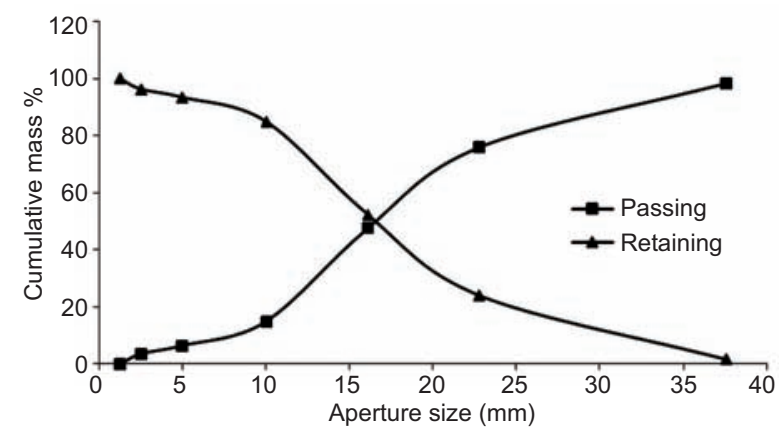

Fig. 2. Graph between aperture size and cumulative mass percentage.
Table 2. Summary of results of proximate analysis

\begin{tabular}{lc}
\hline \hline Characteristic & Value \\
\hline Moisture content (\%) & 3.13 \\
Ash content (\%) & 32.40 \\
Volatile matter (\%) & 34.07 \\
Fixed carbon (\%) & 30.40 \\
Total sulphur (\%) & 5.60 \\
Calorific value (Kcal/kg) & 4753 \\
\hline \hline
\end{tabular}

Padhrar coal to sub-bituminous C type class (ASTM D388). It also contains higher amounts of ash and sulphur which restrict its use in power generation and cement manufacturing.

Fractionation method. The results of ash and sulphur determination tests performed on all the seven fractions are given in Table 3. It can be seen that vast variations exist in the values of ash and sulphur at various coal particle sizes. It is interesting to note that the largestsized fraction $(+26.670 \mathrm{~mm})$ has the highest amount of ash contents while the lowest values of total sulphur percentage are also found in the same size class. The ash contents were the lowest for the medium-sized fraction i.e., for the size range of $-13.330+6.680 \mathrm{~mm}$. The sulphur contents were the highest in the size range of $-6.680+3.327 \mathrm{~mm}$. The ash contents in other size fractions vary from 30.53 to $35.33 \%$. These abrupt variations in the fractionation analysis of Padhrar coal may be attributed from the complex associations of mineral matter with the organic materials. It may be safely concluded that Padhrar coal contains various minerals in different forms which have associations at different levels of particle size and liberate accordingly. The highest ash contents in the largest-sized fraction may be due to the presence of mineral matter in the form of nodules or bands at larger sizes. When these

Table 3. Results of ash and sulphur determination tests performed on different size fractions of Padhrar coal

\begin{tabular}{lcc}
\hline $\begin{array}{l}\text { Aperture size } \\
(\mathrm{mm})\end{array}$ & $\begin{array}{c}\text { Average ash content } \\
(\%)\end{array}$ & $\begin{array}{c}\text { Total sulphur } \\
(\%)\end{array}$ \\
\hline+26.670 & 48.96 & 3.430 \\
$-26.670+18.860$ & 30.63 & 5.280 \\
$-18.860+13.330$ & 34.33 & 5.490 \\
$-13.330+6.680$ & 25.30 & 4.935 \\
$-6.680+3.327$ & 35.33 & 7.050 \\
$-3.327+1.680$ & 32.40 & 6.556 \\
-1.680 & 30.53 & 6.934 \\
\hline \hline
\end{tabular}


large-sized particles are broken, these nodules are fragmented into very fine particles which go down into the smaller-sized fractions leaving more organic rich coal particles in the medium-sized fractions.

X-ray diffraction analysis. Diffractogram of Padhrar coal sample is shown in Fig. 3 while Table 4 presents the major minerals identified by the peak pattern. These minerals are kaolinite, quartz and pyrite.

Megascopic and microscopic analysis. Megascopic and microscopic studies were also performed on Padhrar coal samples. Figure 4 shows bands and nodules of quartz packed in the coal. It may be noted that quartz is present in the form of amalgamates of loosely adhered fine particles. The size of these amalgamates varies approximately from $5 \mathrm{~mm}$ to greater than $25 \mathrm{~mm}$. These masses of quartz are found to be the major reason of higher ash contents at larger coal particle sizes. Since these amalgamates consist of fine particles loosely bound together, when the lumps of coal are broken, they are separated from the coal and disintegrate into individual fine grains. These disintegrated fine grains ultimately go into the finer fractions during sieve analysis, leaving the organic rich coal particles in the middle fractions.

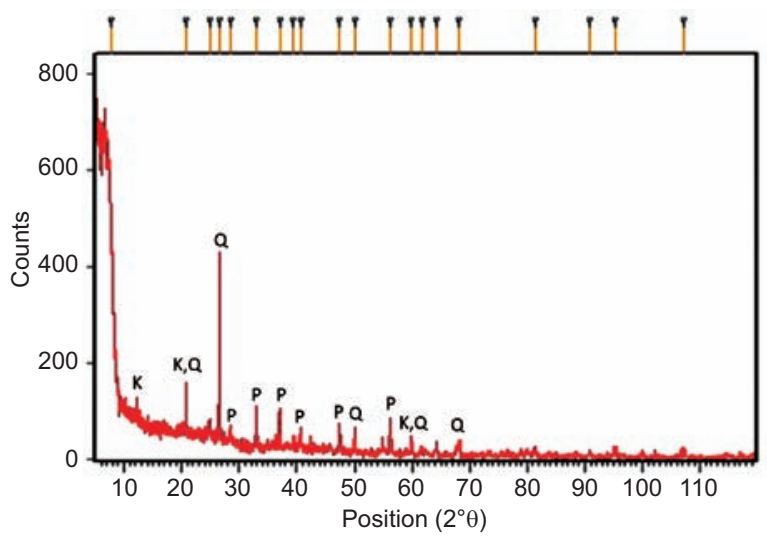

Fig. 3. X-ray diffractogram of Padhrar coal sample ( $\mathrm{K}=$ Kaolinit; $\mathrm{Q}=\mathrm{Quartz} ; \mathrm{P}=$ Pyrite).

Table 4. Pattern list of Padhrar Coal

\begin{tabular}{lccc}
\hline \hline Ref. Code & $\begin{array}{c}\text { Compound } \\
\text { name }\end{array}$ & $\begin{array}{c}\text { Chemical } \\
\text { formula }\end{array}$ & Score \\
\hline $00-001-0527$ & Kaolinite & $\mathrm{Al}_{2} \mathrm{Si}_{2} \mathrm{O}_{5}(\mathrm{OH})_{4}$ & 12 \\
$00-005-0490$ & Quartz & $\mathrm{SiO}_{2}$ & 25 \\
$00-042-1340$ & Pyrite & $\mathrm{FeS}_{2}$ & 16 \\
\hline \hline
\end{tabular}

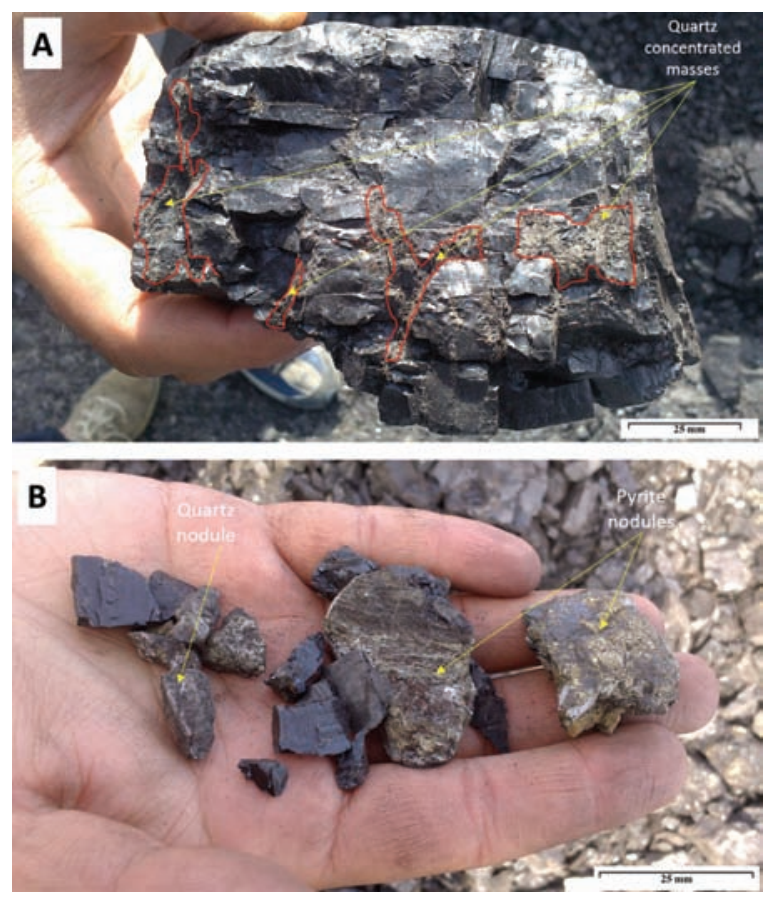

Fig. 4. (A) Lump of coal containing quartz particles in the form of concentrated masses and bands, (B) Quartz and pyrite nodules along with coal particles resulted by the breakage of a coal lump.

Figure 5 shows that pyrite is present in various forms in the Padhrar coal. It is found both in thick and thin bands as well as in the form of nodules. These bands or nodules are relatively smaller than the quartz masses, having greater adherence among the particles. When the coal lumps are broken, these nodules and bands separate from the organic materials and pass down into the medium sized coal fractions due to their relatively larger size. This results an increased total sulphur percentage in the medium sized $(-6.680+3.271 \mathrm{~mm})$ coal particles. In Fig. 5(B) a clay rich coal band can be seen at the left side just before the pyrite nodule. It represents that clayey material is intimately associated with organic matter and does not liberate at coarser sizes, thus causing higher ash values in lower size classes.

Figure 6 presents the microscopic photographs of selected Padhrar coal pieces taken in reflected light by using MM6C-AF-2 microscope. A very thin band of quartz (white) can be seen in the top left corner of the picture. Pyrite particles (golden colour) are unevenly distributed in the coal while clayey particles (dirty white) are associated with coal matrix at finer sizes. 

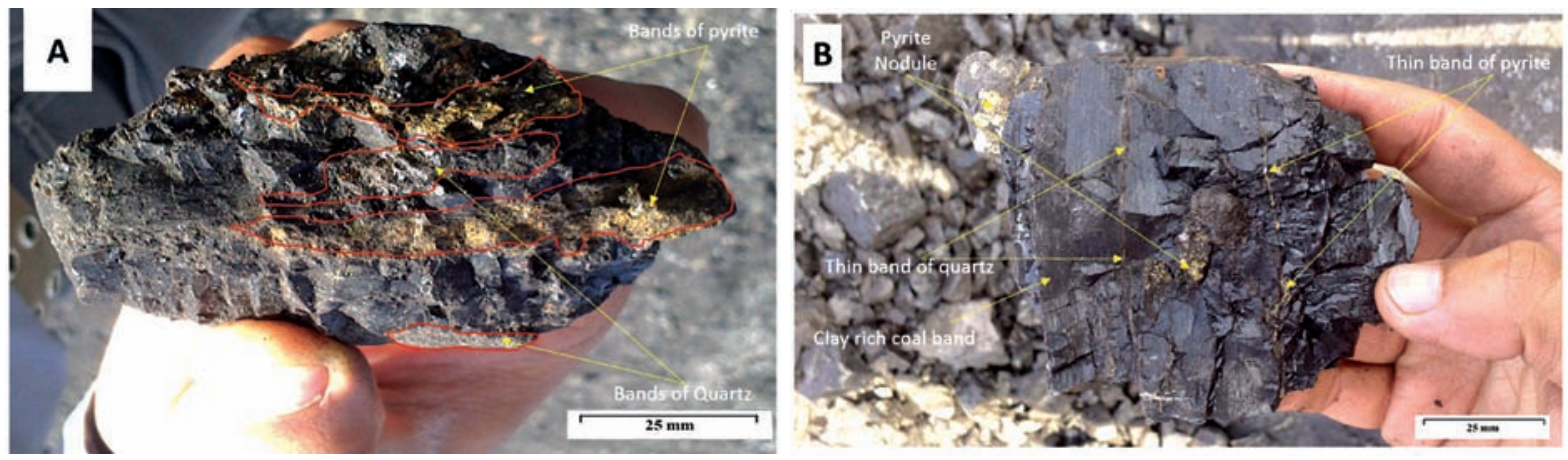

Fig. 5. (A) Pyrite and quartz bands of medium thickness in the coal, (B) Pyrite nodules and thin bands in the coal lump.
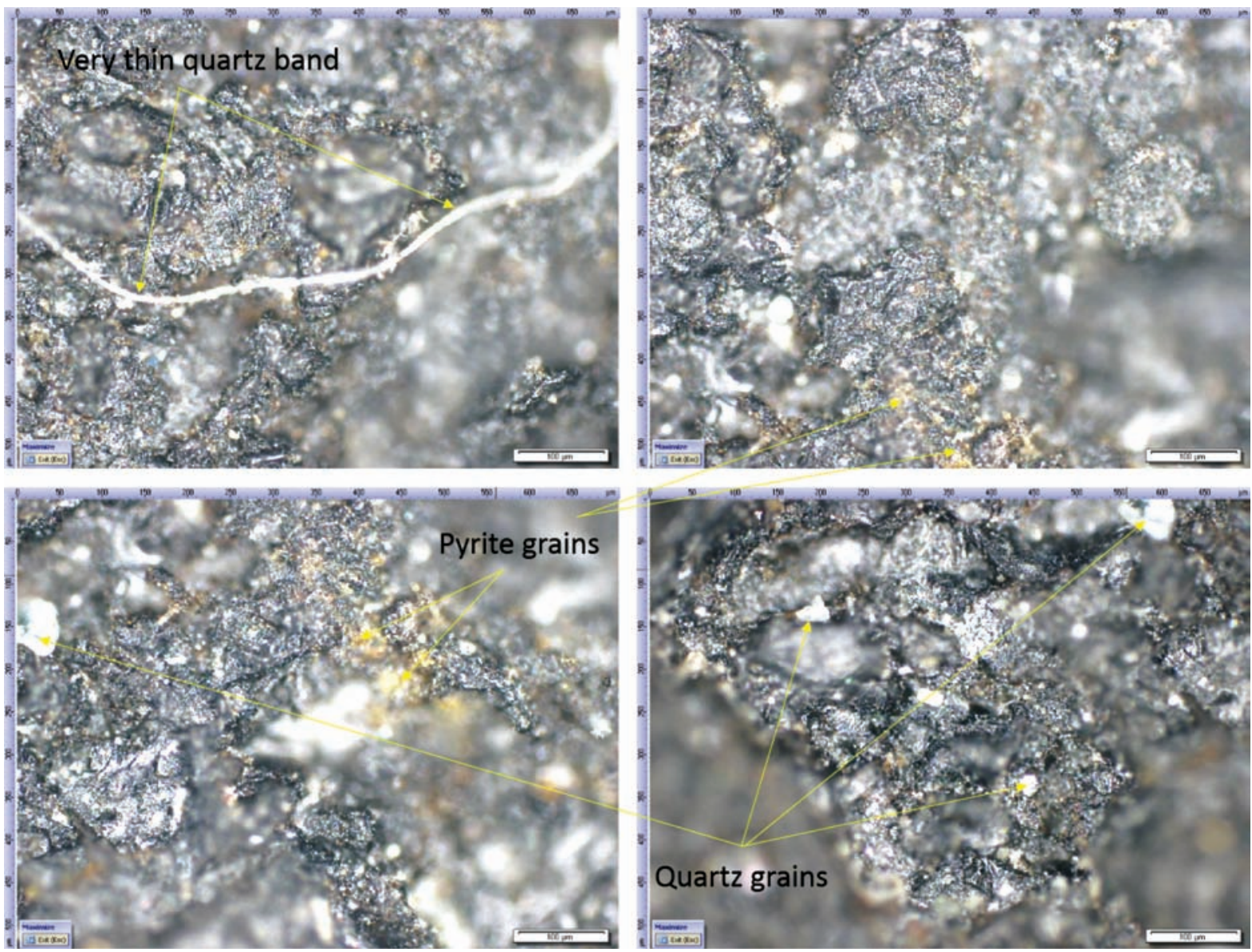

Fig. 6. Microscopic views of coal particles.

All the above results confirm that the Padhrar coal exhibits both epigenetic and syngenetic nature. Mineral matter is present in the form of large nodules, bands, and amalgamates of fine materials as well as in the form of finer particles intimately associated with coal matrix at very small size.

\section{Conclusion}

This research work was conducted to assess the quality and liberation characteristics of Padhrar coal. The results of proximate analysis categorized the Padhrar coal into sub-bituminous $\mathrm{C}$ type class. It was also showed that Padhrar coal contained high amount of sulphur and 
mineral matter. Sieve analysis revealed that more than $83 \%$ of the coal lied in the medium particle size range of $-26.670+6.680 \mathrm{~mm}$. The results of fractionation analysis indicated that most of the sulphur was found in the smaller sized fractions having particle size less than $6.680 \mathrm{~mm}$ while most of the ash was found to be associated at larger particle size $(+26.670 \mathrm{~mm})$ and at relatively smaller particle size $(-6.680 \mathrm{~mm})$. X-ray diffraction (XRD) studies showed the presence of three major minerals namely; kaolinite, pyrite and quartz. The megascopic and microscopic analysis confirmed their presence. These minerals were found to be present in the form of nodules of different sizes, thick and thin bands, fine particles intimately associated with coal matrix, and amalgamates of fine mineral particles concentrated at different spots.

\section{References}

ASTM, 2004. Annual Book of ASTM Standards, vol. 05.06. American Society for Testing and Materials, West Conshohocken, PA. Specifically:

- ASTM D 388. Classification of coals by rank.

- ASTM D-2234. Standard Practice for Collection of a Gross Sample of Coal

- ASTM D 3173. Standard Test Method for Moisture in the analysis Sample of Coal and Coke.

- $\quad$ ASTM D 3174. Standard Test Method for Ash in the analysis Sample of Coal and Coke.

- ASTM D 3175. Standard Test Method for Volatile Matter in the analysis Sample of Coal and Coke.

- ASTM D-6883. Standard Practice for Manual Sampling of Stationary Coal from Railroad Cars, Barges, Trucks and Piles.

- ASTM E 775-87. Standard Test Methods for Total Sulphur in the Analysis Sample of Refuse-Derived Fuel.

Cloke, M., Lester, E., Belghazi, A. 2002. Characterisation of the properties of size fractions from ten world coals and their chars produced in a drop-tube furnace. Fuel, 81: 699-708.

Creelman, R.A., Ward, C.R. 1996. A scanning electron microscope method for automated, quantitative analysis of mineral matter in coal. International Journal of Coal Geology, 30: 249-269.

Liu, Y., Gupta, R., Sharma, A., Wall, T., Butcher, A., Miller, G., Gottlieb, P., French, D. 2005. Mineral matter-organic matter association characterization by QEMSCAN and applications in coal utilisation. Fuel, 84: 1259-1267.
López, I.C., Ward, C.R. 2008. Composition and mode of occurrence of mineral matter in some Colombian coals. International Journal of Coal Geology, 73: 3-18.

Ritz, M., Klika, Z. 2010. Determination of minerals in coal by methods based on the recalculation of the bulk chemical analyses. Acta Geodynamica et Geomaterialia, 7: 453-460.

Saikia, B.K., Boruah, R.K., Gogoi, P.K. 2007. FT-IR and XRD analysis of coal from Makum coalfield of Assam. Journal of Earth System Science, 116: 575-579.

Shahzad, M., Tariq, S.M., Iqbal, M., Arshad, M., Saqib, S. 2015. An assessment of cleaning amenability of salt range coal through physical cleaning methods. Pakistan Journal of Scientific and Industrial Research, Series A: Physical Sciences, 58: 74-78.

Snowden, 2010. Coal Resources of the Salt Range and Trans Indus Range, Punjab.

Spears, D.A., Booth, C.A. 2002. The composition of size-fractionated pulverised coal and the trace element associations. Fuel, 81: 683-690.

Ural, S. 2007. Quantification of crystalline (mineral) matter in some Turkish coals using interactive Rietveld-based X-ray diffractometry. International Journal of Coal Geology, 71: 176-184.

Valentim, B., Lemos de Sousa, M.J., Abelha, P., Boavida, D., Gulyurtlu, I. 2006. The identification of unusual mircoscopic features in coal and their derived chars: Influence on coal fluidized bed combustion. International Journal of Coal Geology, 67: 202-211.

Vassilev, S.V., Tascon, J.M.D. 2003. Methods for characterization of inorganic and mineral matter in coal: a critical overview. Energy and Fuels, 17: 271-281.

Vassilev, S.V., Vassileva, C.G. 1996. Occurrence, abundance and origin of minerals in coals and coal ashes. Fuel Processing Technology, 48: 85-106.

Ward, C.R. 2002. Analysis and significance of mineral matter in coal seams. International Journal of Coal Geology, 50: 135-168.

Ward, C.R., Matulis, C.E., Tylor, J.C., Dále, L.S. 2001. Quantification of mineral matter in Argonne Premium Coals using interactive Rietveld-based $\mathrm{X}$-ray diffraction. International Journal of Coal Geology, 46: 67-82.

Wertz, D.L., Collins, L.W. 1998. Using X-ray methods to evaluate the combustion sulphur minerals and graphitic carbon in coals and ashes. American Chemical Society, Division of Fuel Chemistry, 33: 247-252. 